\title{
CBTL Design Case Summary Conventional Feedstock Supply System -- Herbaceous
}

Christopher Wright Erin M. Searcy

February 2012

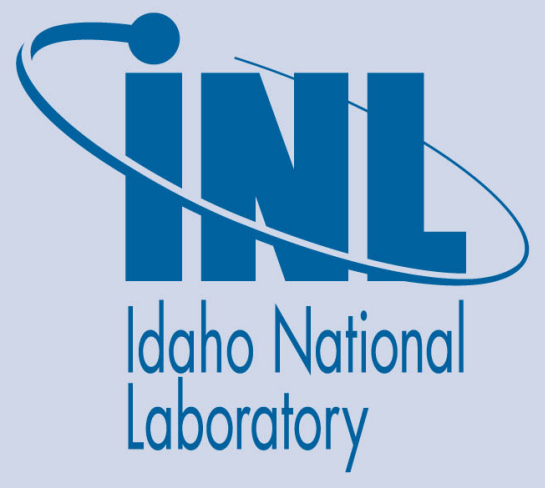

The INL is a U.S. Department of Energy National Laboratory operated by Battelle Energy Alliance 
INL/EXT-12-25021

\title{
CBTL Design Case Summary Conventional Feedstock Supply System -- Herbaceous
}

\author{
Christopher Wright
}

Erin M. Searcy

February 2012

\begin{abstract}
Idaho National Laboratory
Idaho Falls, Idaho 83415
\end{abstract}

http://www.inl.gov

\author{
Prepared under \\ a Work for Others Agreement \\ and for the \\ U.S. Department of Energy \\ Under DOE Idaho Operations Office \\ Contract DE-AC07-05ID14517
}




\section{DESIGN CASE SUMMARY}

\section{Conventional Feedstock Supply System-Herbaceous}

A conventional bale feedstock design has been established that represents supply system technologies, costs, and logistics that are achievable today for supplying herbaceous feedstocks as a blendstock with coal for energy production. Efforts are made to identify bottlenecks and optimize the efficiency and capacities of this supply system, within the constraints of existing local feedstock supplies, equipment, and permitting requirements.

The feedstock supply system logistics operations encompass all of the activities necessary to move herbaceous biomass feedstock from the production location to the conversion reactor ready for blending and insertion (Figure 1). This supply system includes operations that are currently available such that costs and logistics are reasonable and reliable. The system modeled for this research project includes the uses of field-dried corn stover or switchgrass as a feedstock to annually supply an 800,000 dry metric (DM) ton conversion facility (Table 1). A schematic of the system is shown in Figure 1.

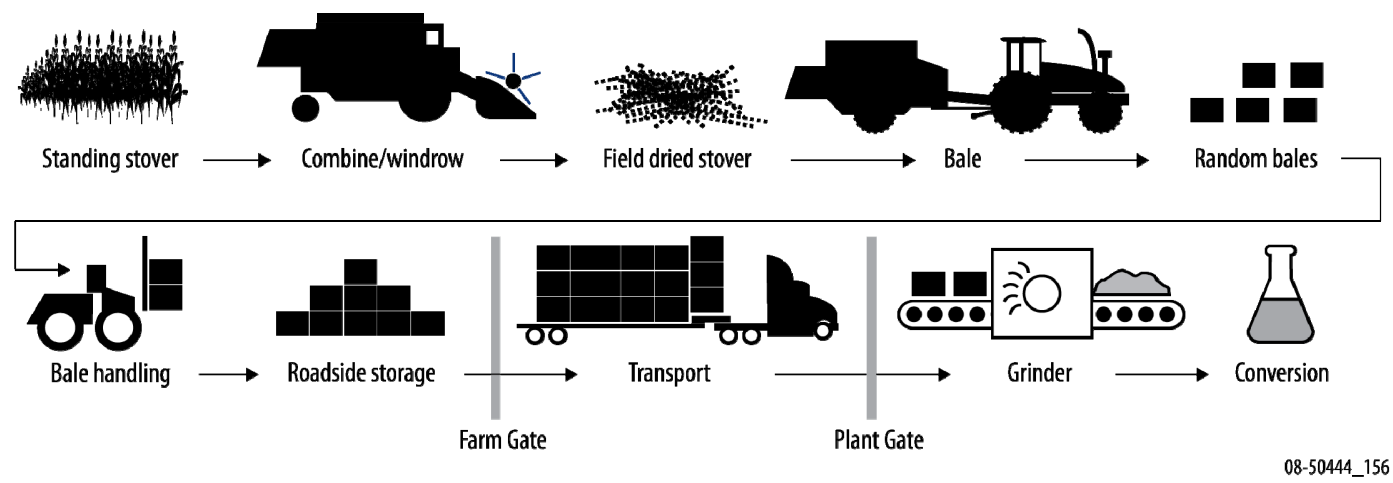

Figure 1. INL researches material properties and equipment performance from the point of harvest to infeed into the conversion reactor. The Conventional Bale biomass feedstock supply system incorporates existing or near-term equipment and practices.

In order to establish a baseline system, a set of parameters has been established so that the modeled supply system design can feed conversion facilities based on previously reported biochemical ${ }^{1}$ pathways (Table 1). Even though the current project is not focused on biochemical conversion as the end use of the feedstock, the design, and thus the feedstock modeled, can be used to feed a thermochemical or direct combustion facility without any changes to the base assumptions. Thus, the modeled design uses field-dried corn stover or switchgrass as the feedstocks to supply a conversion facility that depends on a year-round biomass delivery schedule with 800,000 DM tons of biomass annually.

\footnotetext{
${ }^{1}$ Aden A, M Ruth, K Ibsen, J Jechura, K Neeves, J Sheehan, B Wallace, L Montague, A Slayton, J Lukas (2002) Lignocellulosic Biomass to Ethanol Process Design and Economics Utilizing Co-Current Dilute Acid Prehydrolysis and Enzymatic Hydrolysis for Corn Stover, NREL/TP-510-32438, http://www.nrel.gov/docs/fy02osti/32438.pdf
} 
Table 1. The Conventional Bale-Corn Stover/Switchgrass supply system scenario is scaled to support current baseline conversion facility designs.

\begin{tabular}{|lc|}
\hline & Corn Stover/Switchgrass \\
\hline Plant Operation Size (delivered tons & a \\
Feedstock Harvested Annually & b00,000 DM ton/yr \\
\% Supply Area Under Cultivation & 842,100 DM ton \\
\% Cropland in Supply Area Cultivated in Corn & $50 \%$ \\
\% Farmer Participation & $50 \%$ \\
Acres Harvested Annually & $50 \%$ \\
Feedstock Supply Radius & 261,900 \\
\hline
\end{tabular}

a. U.S. short ton $=2,000 \mathrm{lb}$.

b. Extra tonnage harvested to account for supply system losses.

In the Conventional Bale scenarios, stover/switchgrass is left in the field after harvest. It is then windrowed and dried in the field and later baled. The baled material is stacked at roadside where it is covered and stored until needed at the conversion facility. The stored bales are transported via truck to the conversion facility, where they are received and undergo further processing and blending to meet specifications for the conversion process.

In order for the baled material to meet conversion specifications it is size-reduced at the conversion facility prior to blending. The modeled conversion size specification is a nominal particle size of 3/16inch (based on grinder screen size). Through experimentation, this size of particles has exhibited satisfactory flow and blending characteristics necessary for a suitable blendstock with coal. Table 2 shows the mean particle size of the corn stover (CS) and switchgrass (SW) material compared with pine (PC). The mean particle size for corn stover is $0.582 \mathrm{~mm}$ and for switchgrass is $0.678 \mathrm{~mm}$ with a distribution represented in Figure 2.

Table 2. Particle characteristics. $X_{c}$ min represents the geometric mean diameter $\left(d_{g w}\right)$ with the geometric mean diameter standard deviation $\left(S_{g w}\right)$ shown in parenthesis. The sphericity (SHPT) and aspect ratio are also listed, where the aspect ratio is the ratio between $X_{c} \min$ and $X_{f e} \max$.

\begin{tabular}{|l|c|c|c|}
\hline \multicolumn{1}{|c|}{ Particle Characteristics } & CS & SW & PC \\
\hline $\mathrm{X}_{\mathrm{c}} \min \left(\mathrm{s}_{\mathrm{gw}}\right), \mathrm{mm}$ & $0.582(0.817)$ & $0.678(1.122)$ & $0.735(0.771)$ \\
\hline $\mathrm{X}_{\mathrm{fe}} \max \left(\mathrm{s}_{\mathrm{gw}}\right), \mathrm{mm}$ & $1.351(2.076)$ & $1.744(2.857)$ & $1.652(1.784)$ \\
\hline $1 / \mathrm{SPHT}^{b}$ & $2.456(0.164)$ & $2.784(0.052)$ & $2.525(0.029)$ \\
\hline Aspect Ratio $^{b}$ & $0.475(0.007)$ & $0.431(0.002)$ & $0.470(0.002)$ \\
\hline
\end{tabular}

${ }^{a}$ Number enclosed in the parenthesis were standard deviation with $\mathrm{n}=3$

${ }^{\mathrm{b}}$ Aspect ratio and SPHT are dimensionless parameters. 


\section{HERBACEOUS BIOMASS FEEDSTOCK SUPPLY SYSTEM}
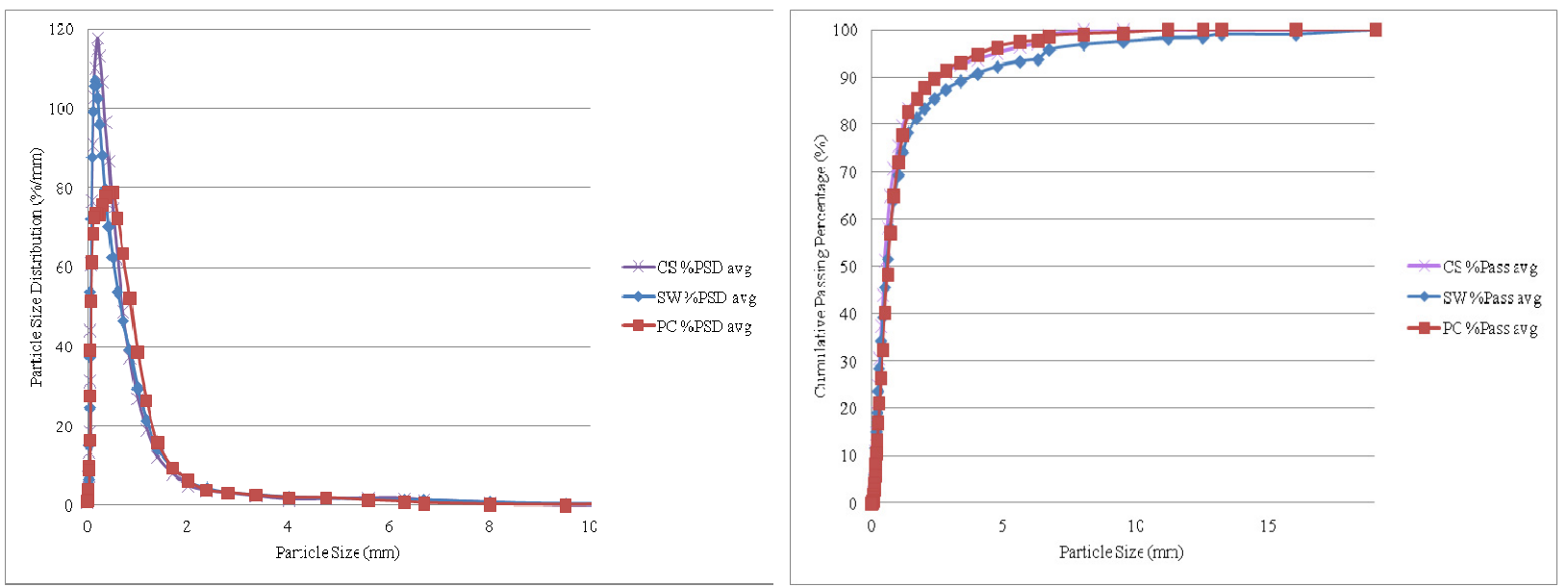

Figure 2. Particle size distribution. The derivative of the cumulative passing size distribution, $\% / \mathrm{mm}$, (Rhodes \& Ebooks, 2008), (4a) and cumulative passing,\% (4b) of nominal 3/16-inch pine grind.

\section{Conventional Design Costs}

Costs for the conventional bale design used in this project were modeled using the feedstock supply system model developed at INL. A baseline scenario was established using metrics that are consistent with current biochemical conversion pathway reports, since these reports use herbaceous biomass as the feedstock source. These costs include labor, fuel, material, and equipment (comprised of owner and operating costs) for all operations necessary to move the biomass from standing in the field to the point of blending with other feedstock or directly feeding the conversion process. The modeled costs are shown in Table 2. 
Table 2. Unit operation costs in a Conventional Feedstock Supply System (2007 USD per dry matter (DM) ton*), for the scenario using cornstover/switchgrass as a feedstock.

\begin{tabular}{|l|c|}
\multicolumn{1}{|c|}{ Cost Summary in 2007 USD } & \\
\hline \multicolumn{1}{|c|}{} & \$DM ton \\
\hline Total Feedstock Cost & $\mathbf{5 2 . 0 0}$ \\
\hline Total Logistics Cost & $\mathbf{3 6 . 1 0}$ \\
\hline Total Grower Payment ${ }^{2}$ & $\mathbf{1 5 . 9 0}$ \\
\hline Harvest \& Collection & $\$ 13.80$ \\
\hline Total Cost Contribution & $\$ 5.20$ \\
\hline Capital Cost Contribution & $\$ 8.60$ \\
\hline Operating Cost Contribution & \\
\hline Storage and Queuing & $\$ 2.65$ \\
\hline Total Cost Contribution & $\$ 1.40$ \\
\hline Capital Cost Contribution & $\$ 1.25$ \\
\hline Operating Cost Contribution & $\$ 10.65$ \\
\hline Preprocessing & $\$ 1.80$ \\
\hline Total Cost Contribution & $\$ 8.85$ \\
\hline Capital Cost Contribution & \\
\hline Operating Cost Contribution & $\$ 9.00$ \\
\hline Transportation \& Handling & $\$ 1.50$ \\
\hline Total Cost Contribution & $\$ 7.50$ \\
\hline Capital Cost Contribution & \\
\hline Operating Cost Contribution & \\
\hline
\end{tabular}

* Grower payment estimates provided by Oak Ridge National Laboratory

\section{Summary}

This Conventional Bale design is a baseline design for meeting the material specification targets set forth in the CBTL Project between INL and GE Global Research. This analysis reveals key parameters and unit operations that contribute to the cost of a conventional herbaceous bale design. The challenges faced by this design, in terms of cost, are driven by the logistics of the system where moving large quantities of a bulky, unstable, non-flowable material is inherent. Despite these challenges, the technology exists that will allow for relatively large amounts of herbaceous material to be harvested, collected, preprocessed, and delivered to a conversion facility as a standalone feedstock or as a blendstock for energy production.

\footnotetext{
${ }^{2}$ Langholtz, M., Graham, R.C., Eaton, L., Perlack, R., Hellwinckel, C., De la Torre Ugarte, D., in review. Price Projections of Feedstocks for Biofuels and Biopower in the U.S. Energy Policy.
} 


\section{Motivation for a Commodity-Driven System}

The U.S. DOE aims to displace $30 \%$ of the 2004 gasoline use with biofuels ( 60 billion gal/yr) by 2030. Of those 60 billion gallons, 15 billion are projected to come from grains, and the remaining 45 billion from lignocellulosic resources. This means that of the 700 million DM tons of biomass required annually, 530 million DM tons will come from a diverse variety of herbaceous and woody lignocellulosic biomass resources (also referred to as "cellulosic" biomass). In order for the biofuels industry to be a selfsustaining enterprise, the lignocellulosic feedstock supply system logistics (all processes involved in getting the biomass from the field to the conversion facility) cannot consume more than $25 \%$ of the total cost of the biofuel production.

While national assessments ${ }^{3}$ identify sufficient biomass resource to meet the production targets, much of that resource is inaccessible using current biomass supply systems because of unfavorable economics. Therefore, conventional biomass supply systems are incapable of meeting these long-term biomass use goals. Increasing the demand for lignocellulosic biomass introduces many logistical challenges to providing an economic, efficient, and reliable supply of quality feedstock to the biorefineries.

The design report, Uniform-Format Solid Feedstock Supply System: A Commodity-Scale Design for Bulk Solid Lignocellulosic Biomass, documents an approach to address these logistic challenges by implementing a strategy of incremental change from existing biomass supply systems to economic and reliable commodity-scale supply systems that provide uniform, aerobically stable, quality-controlled feedstocks to biorefineries. This type of approach has been demonstrated and proven successful for feed grains. For herbaceous lignocellulosic resources, these design increments are termed "Conventional Bale," which reflects current practice and was presented in this case study, "Pioneer Uniform," which uses current or very near-term technologies and offers incremental improvements over the Conventional Bale system, and "Advanced Uniform," which meets all cost and supply targets and requires some conceptual equipment, such as a single-pass harvester, to provide a commodity-scale bulk solid feedstock.

The Pioneer Uniform design enables the transition from the Conventional Bale to the Advanced Uniform supply system by developing the supply chain infrastructure required for forward-deployed preprocessing. The Advanced Uniform system formats biomass of various types (i.e., corn stover, switchgrass) and physical characteristics (i.e., bulk densities, moisture content) into a standardized format early in the supply chain. This uniform material format allows biomass to be handled as a commodity that can be bought and sold in a market, vastly increasing its availability to the biorefinery and enabling large-scale facilities to operate with a continuous, consistent, and economic feedstock supply. The commodity-scale system also releases biorefineries from contracting directly with local farmers for biomass feedstocks. Figure 3 shows a schematic of the end-state commodity supply system for all types of lignocellulosic biomasses resources.

3. Perlack RD, LL Wright, AF Turhollow, RL Graham, BJ Stokes, DC Erbach (2005) Biomass as Feedstock for a Bioenergy and Bioproducts Industry: The Technical Feasibility of a Billion-Ton Annual Supply, DOE/GO-102005-2135. 


\section{Conventional Feedstock Supply System}

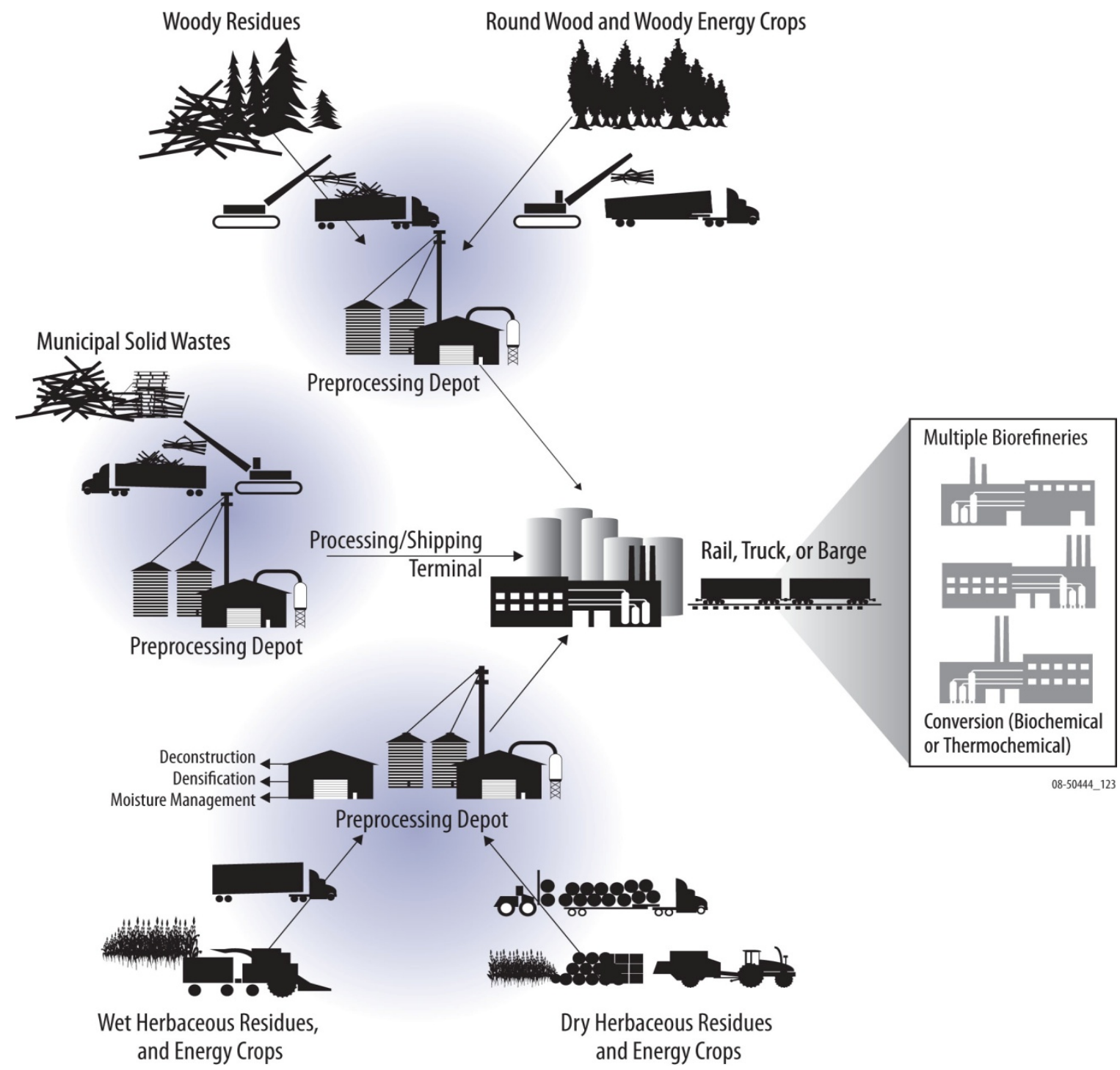

Figure 3. The Advanced-Uniform format feedstock supply system resembles the grain commodity system, which manages crop diversity at the point of harvest and/or the storage elevator, allowing subsequent supply system infrastructure to be similar for all biomass resources. 